Original research article

\title{
Antioxidant and anti-inflammatory mechanisms of polyphenols isolated from virgin coconut oil attenuate cadmium-induced oxidative stress-mediated nephrotoxicity and inflammation in rats
}

\author{
Ademola C. Famurewa ${ }^{\mathrm{a}, *}$, Abumchukwu J. Ejezie ${ }^{\mathrm{b}}$, Chioma S. Ugwu-Ejezie ${ }^{\mathrm{c}}$, \\ Ebele J. Ikekpeazu ${ }^{\mathrm{d}}$, Fidelis E. Ejezie ${ }^{\mathrm{d}}$ \\ a Federal University, Ndufu-Alike, Faculty of Basic Medical Sciences, Department of Medical Biochemistry, Ikwo, Ebonyi State, Nigeria \\ ${ }^{\mathrm{b}}$ University of Nigeria, Enugu Campus, College of Medicine, Department of Anatomy, Enugu State, Nigeria \\ ${ }^{\mathrm{c}}$ University of Nigeria Teaching Hospital, Department of Haematology/Immunology, Ituku-Ozalla, Enugu State, Nigeria \\ ${ }^{\mathrm{d}}$ University of Nigeria, Enugu Campus, College of Medicine, Department of Medical Biochemistry, Enugu State, Nigeria
}

\section{A R T I C L E I N F O}

\section{Article history:}

Received 11 July 2017

Received in revised form 24 December 2017

Accepted 5 February 2018

Available online 10 February 2018

\section{Keywords}

Polyphenols

Cadmium

Virgin coconut oil

Nephrotoxicity

Oxidative stress

Inflammation

\begin{abstract}
A B S T R A C T
Purpose: Cadmium (Cd) is a classic cumulative nephrotoxicant and literature suggests that its toxicity is associated with oxidative stress and inflammation which contribute to pathologies in various tissues. We sought to investigate whether polyphenols isolated from virgin coconut oil (VCO) would modulate nephrotoxicity and inflammation induced by $\mathrm{Cd}$ in rats.

Methods: Rats were administered polyphenols prior to and along with Cd ( $5 \mathrm{mg} / \mathrm{kg}$, orally) for 7 weeks. Serum markers of renal damage, interleukin-6 (IL-6), C-reactive protein (CRP) and nitric oxide (NO) were evaluated; renal activities of antioxidant enzymes, as well as malondialdehyde (MDA) and reduced glutathione $(\mathrm{GSH})$ content were determined. Histopathologic alterations were evaluated to define kidney damage.

Results: Cadmium exposure induced nephrotoxicity and oxidative stress evident by significantly increased serum levels of creatinine, urea, and uric acid along with remarkable depression in renal activities of antioxidant enzymes and GSH with prominent increase in MDA. Inflammatory markers IL-6, CRP and NO were significantly increased and confirmed by histopathology. Sub-chronic administration of VCO polyphenols attenuated the Cd-induced biochemical alterations compared to Cd control with remarkably improved histopathological observations.

Conclusion: The findings showed that VCO polyphenol supplementation protects against Cd-induced nephrotoxicity via its antioxidant and anti-inflammatory mechanisms in rats.

(c) 2018 Faculty of Health and Social Sciences, University of South Bohemia in Ceske Budejovice. Published
\end{abstract} by Elsevier Sp. z o.o. All rights reserved.

\section{Introduction}

Cadmium (Cd) is a hazardous element and non-essential transition metal of worldwide concern because its toxicity represents a significant health hazard to humans and animals (Colacino et al., 2014). It persists in the environment and penetrates into human foodstuffs and water from natural and anthropogenic sources (Barregard et al., 2016; Bernard, 2016; Hagar and Almalki,

\footnotetext{
* Author for correspondence: Federal University, Ndufu-Alike, Faculty of Basic Medical Sciences, Department of Medical Biochemistry, Ikwo, Ebonyi State, Nigeria E-mail address: ademola.famurewa@funai.edu.ng (A.C. Famurewa).
}

2014). Cadmium is considerably absorbed in the lungs thereby representing a major source of exposure for the non-occupationally exposed population (Barregard et al., 2016; Nordberg et al., 2015).

Cadmium is a classic cumulative nephrotoxicant implicated in renal pathologies. The kidney is the primary target for Cd toxicity. It accumulates, particularly in the renal tubular cells to cause glomerular and tubular dysfunction (Bernard, 2016; Järup and Akesson, 2009). Strikingly, there is a growing body of literature indicating that $\mathrm{Cd}$-induced nephrotoxicity can result from even low levels of $\mathrm{Cd}$ exposure and that women, children, and individuals with confounding health conditions, such as diabetes, may be especially susceptible to amplified Cd toxicity (Prozialeck and Edwards, 2012; Satarug et al., 2010). 
However, although research effort to identify mechanisms of Cd toxicity is formidable, reactive oxygen species (ROS), oxidative stress development and inflammation are often implicated as critical underlying mechanisms of Cd nephrotoxicity (Hagar and Almalki, 2014; Ojo et al., 2014; Renugadevi and Prabu, 2009). Nephrotoxic action of $\mathrm{Cd}$ is associated with its free radical inducing mechanism. In chronic Cd exposure, proximal tubular cells are sensitive to $\mathrm{Cd}$ accumulation to trigger epithelial cell dysfunction associated with oxidative stress (Prozialeck and Edwards, 2012). Although Cd is not a Fenton metal, it induces generation of ROS and oxidative stress via indirect mechanism reported consistently in Cd-mediated renal injury (Fagerberg et al., 2016; Liu et al., 2009). Cadmium is suggested to bind indirectly to intracellular thiols in reduced glutathione, disrupting sulfhydryl homeostasis and suppressing antioxidant defence mechanism to promote oxidative cellular effects (Patra et al., 2011; Vidal et al., 2015). Moreover, oxidative stress-induced inflammation is suggested to be integrated into mechanism by which Cd exposure increases disease risk (Shahani et al., 2016). Previous studies show that oxidative stress provokes the release of pro-inflammatory mediators, including C-reactive protein (Khanna et al., 2015).

An established approach to combat metal toxicity is chelation therapy. However, the undesirable side effects of the current therapies against metal toxicity highlight the need to intensify research aimed to develop new agents able to prevent or retard toxicity progression. More so, none of the chelation therapies for Cd toxicity is approved for clinical use currently (Zhai et al., 2015). Natural products contain antioxidant polyphenols that may inhibit nephrotoxicity associated with oxidative stress in experimental animals (Farooqui et al., 2017).

Virgin coconut oil (VCO) is obtained from fresh, mature kernel of the coconut by mechanical or natural means, with or without the use of heat and without undergoing chemical refining (Marina et al., 2009). Recent research findings suggest phenolic-dependent antioxidant properties of VCO in animal models (Seneviratne et al., 2009). Phenolic acids and flavonoids such as ferulic, caffeic, p-coumaric, vanillic and syringic acids and catechin found in VCO have been associated with beneficial health effects in animal studies (Arunima and Rajamohan, 2013; Akinnuga et al., 2014; Famurewa et al., 2017; Marina et al., 2009; Rahim et al., 2017). The potent antioxidant and anti-inflammatory property of VCO polyphenols are recently reported against complete Freund's adjuvant-induced arthritis (Vysakh et al., 2014) and pro-oxidant mediated cell death (Illam et al., 2017). Given the widespread nature of $\mathrm{Cd}$, the emerging role of VCO that is affordable and amenable to daily diet in metal toxicity need considerable attention. To our knowledge, there is no biochemical investigation carried out on potential of VCO polyphenols in the prevention of Cd-induced toxicity, nephrotoxicity or inflammation in the published literature. Therefore, this study was designed to investigate whether VCO polyphenols would exert beneficial effect on nephrotoxicity, inflammation and oxidative stress induced by $\mathrm{Cd}$ exposure in rats.

\section{Materials and methods}

\section{Chemicals}

Cadmium (as cadmium chloride, $\mathrm{CdCl}_{2}$ ), 1, 1-diphenyl-2picrylhydrazyl (DPPH) and gallic acid were obtained from Sigma-Aldrich Chemical Co., USA. Folin-Ciocalteu reagent was purchased from Merck Co. (Darmstadt, Germany). Methanol and nhexane were purchased from Loba Chemie Pvt. Ltd. Mumbai, India. Reagents used for the assays were commercial test kits and products of Randox, UK; Biotrust Diagnostics, USA; R\&D Systems,
Inc. USA; Hi Media Laboratories, Mumbai, India. All other chemicals used were obtained from local commercial suppliers.

\section{Animals}

Forty-eight male albino rats of Wistar strain (100-120 g) were used as experimental animals in the present investigation. The rats were housed in Animal Facility of the Department of Biochemistry, Ebonyi State University, Nigeria, under standard environmental conditions $\left(25^{\circ} \mathrm{C}\right.$ and $12 \mathrm{~h}$ light/ $12 \mathrm{~h}$ dark cycle). They were kept in cages with wood chip bedding and allowed free access to standard pellet diet (Vital Feeds Nigeria Ltd, Jos, Nigeria) and clean water ad libitum. The rats were acclimatized one week preceding treatment and were handled in humane manner according to the approved animal experimental procedures of NIH Guidelines for the Care and Use of Laboratory Animals (Guide for the care and the use of laboratory animals, 2011).

\section{Extraction of VCO}

The method according to Nevin and Rajamohan (2004) was used to extract VCO from coconuts (Cocos nucifera). Briefly, the viscous slurry obtained from coconut meat (solid endosperm) was made into a creamy milky solution by the addition of about $400 \mathrm{ml}$ of clean water. The solution was sieved through cheesecloth and the milky filtrate was left standing for $48 \mathrm{~h}$ to separate the creamy top and water layers. The top layer was carefully removed and subjected to mild heating $\left(50^{\circ} \mathrm{C}\right)$ to remove moisture. The floating oil was gently scooped out and filtered into an air-tight container. This oil thus prepared without refining, bleaching and deodorizing was used for isolation of polyphenols administered to rats in the current study.

\section{Extraction of polyphenols from VCO}

Polyphenols in VCO was extracted according to the method described by Nevin and Rajamohan (2004) with slight modification. VCO (10 g) was mixed with $50 \mathrm{ml}$ of n-hexane, and extracted using $20 \mathrm{ml}$ methanol (80\%). The process was repeated three times to ensure complete extraction of polyphenols. The three polyphenol fractions were pooled and the extraction solvent was allowed to evaporate. In vitro antioxidant activity assay of the polyphenol fraction was determined.

\section{In vitro antioxidant assay of polyphenol fraction}

The antioxidant ability of VCO polyphenols was assessed using 1, 1-diphenyl-2-picrylhydrazyl (DPPH) radical according to the method described by Blois (1958). The reducing antioxidant power of VCO polyphenols was evaluated using ferric reducing antioxidant power (FRAP) assay described by Oyaizu (1986). Total phenolic content of the VCO polyphenol fraction was estimated by Folin-Ciocalteu colorimetric method (Wangensteen et al., 2004).

\section{Experimental design}

After 1 week of acclimatization, rats were randomly divided into 6 groups $(n=8)$ and the treatment design was as follows:

- Group 1 (normal control): received clean water (orally, $1 \mathrm{ml} / \mathrm{kg}$ ) for 7 weeks;

- Group 2 (polyphenols = PF control): received PF (orally, $20 \mathrm{mg}$ / $\mathrm{kg})$ for 7 weeks;

- Group 3 (Cd control): received $\mathrm{CdCl}_{2}$ (orally, $5 \mathrm{mg} / \mathrm{kg}$ ) during the last 5 weeks (Renugadevi and Prabu, 2009); 
- Group $4(\mathrm{PF}+\mathrm{Cd} \mathrm{I})$ : received $\mathrm{PF}$ (orally, $10 \mathrm{mg} / \mathrm{kg}$ ) for 7 weeks $+\mathrm{CdCl}_{2}$ (orally, $5 \mathrm{mg} / \mathrm{kg}$ ) during the last 5 weeks;

- Group 5 (PF + Cd II): received PF (orally, $20 \mathrm{mg} / \mathrm{kg}$ ) for 7 weeks $+\mathrm{CdCl}_{2}$ (orally, $5 \mathrm{mg} / \mathrm{kg}$ ) during the last 5 weeks;

- Group 6 (PF + Cd III): received PF (orally, $50 \mathrm{mg} / \mathrm{kg}$ ) for 7 weeks $+\mathrm{CdCl}_{2}$ (orally, $5 \mathrm{mg} / \mathrm{kg}$ ) during the last 5 weeks.

Fasted rats were sacrificed and serum obtained from blood samples. The kidney was dissected out, washed in cold saline solution, dried with tissue paper and weighed. The tissue was minced and homogenized in $0.1 \mathrm{M}$ phosphate buffer $(1: 5 \mathrm{w} / \mathrm{v}, \mathrm{pH}$ 6.4 ) and centrifuged $(4000 \times \mathrm{g}$ for $20 \mathrm{~min})$ to obtain supernatant for renal antioxidant enzyme analyses, reduced glutathione level and malondialdehyde content.

\section{Biochemical analyses}

The kidney function markers were analysed in serum stored at $4{ }^{\circ} \mathrm{C}$ using commercial kits by RANDOX. The renal activity of SOD was assayed by the method of Arthur and Boyne (1985). The activity of CAT assayed by the method of Sinha (1972), while GPx was done according to the method of Paglia and Valentine (1967). The renal GSH level was determined by the method of Exner et al. (2000). Lipid peroxidation was estimated by measuring spectrophotometrically the level of malondialdehyde (MDA) as described by Wallin et al. (1993). Nitric oxide (NO) was estimated using commercial kit based on the Griess reagents (R\&D Systems, USA) according to the method of Green et al. (1982). The concentration of interleukin-6 (IL-6) was analysed by ELISA method with commercially available assay kit (R\&D Systems Inc., USA). C-reactive protein was estimated using method of Andersen and McCarthy (1950) described in TULIP DIAGNOSTICS kit.

\section{Histopathological examination}

Investigation was carried out on kidney samples to evaluate histopathological alterations. Kidney samples were fixed in $10 \%$ buffered formalin for $48 \mathrm{~h}$, dehydrated in ethanol and embedded in paraffin. Kidney section $(5 \mu \mathrm{m})$ was prepared and stained with hematoxylin and eosin stain ( $\mathrm{H} \& \mathrm{E})$ for histopathological examination under light microscope.

\section{Statistical analysis}

All results are expressed as arithmetic mean \pm SEM. Statistical evaluation was conducted using ANOVA followed by Tukey's post-hoc test (SPSS version 22.0 for windows, Inc., Chicago, IL, USA) was used to analyse the results and $p<0.05$ considered significant.

Table 1

Effects of administration of VCO polyphenols and Cd on body weight, kidney weight and relative kidney weight of treated rats.

\begin{tabular}{llll}
\hline Group & Body weight $(\mathrm{g})$ & Kidney weight $(\mathrm{g})$ & Rel. kidney weight $(\%)$ \\
\hline Control & $149.1 \pm 12.6$ & $0.51 \pm 0.02$ & $0.38 \pm 0.05$ \\
PF & $158.6 \pm 6.4$ & $0.52 \pm 0.03$ & $0.32 \pm 0.02$ \\
Cd & $141.2 \pm 5.6$ & $0.48 \pm 0.02$ & $0.34 \pm 0.01$ \\
PF + Cd I & $158.3 \pm 3.6$ & $0.52 \pm 0.01$ & $0.33 \pm 0.01$ \\
PF + Cd II & $151.6 \pm 7.3$ & $0.49 \pm 0.22$ & $0.33 \pm 0.03$ \\
PF + Cd III & $158.9 \pm 8.5$ & $0.54 \pm 0.03$ & $0.34 \pm 0.01$ \\
\hline
\end{tabular}

PF: polyphenols; Cd: cadmium; PF + Cd I: PF (10 mg/kg)+Cd (5 mg/kg); PF + Cd II: PF $(20 \mathrm{mg} / \mathrm{kg})+\mathrm{Cd}(5 \mathrm{mg} / \mathrm{kg}) ; \mathrm{PF}+\mathrm{Cd}$ III: PF $(50 \mathrm{mg} / \mathrm{kg})+\mathrm{Cd}(5 \mathrm{mg} / \mathrm{kg})$. Values are expressed as mean \pm SEM $(n=8)$

\section{Results}

Effects of administration of VCO polyphenols and Cd on body weight and kidney weight of treated rats

Table 1 shows the effect of VCO polyphenols and Cd administration on body weight, kidney weight and relative kidney weight of treated rats at sacrifice. The Cd exposure in Cd-treated group $(5 \mathrm{mg} / \mathrm{kg})$ demonstrated a non-significant decrease $(p>0.05)$ in body weight compared to control. However, the administration of VCO polyphenols $(10,20$ and $50 \mathrm{mg} / \mathrm{kg}$ ) prior to and concurrently with $\mathrm{Cd}$ to rats in $\mathrm{PF}+\mathrm{Cd}$ I, II and III groups showed non-significant increases $(p>0.05)$ in body weight when compared with the $\mathrm{Cd}$-treated rats. The administration of $\mathrm{Cd}(\mathrm{Cd}$ group) decreased absolute kidney weight and relative kidney weight (kidney weight $\div$ body weight $\times 100$ ) non-significantly $(p>0.05)$ compared to control. The VCO polyphenols administration in $\mathrm{PF}+\mathrm{Cd}$ groups raised the kidney weight comparable to control group, although the differences were not statistically significant $(p>0.05)$ compared to $\mathrm{Cd}$ group.

Effects of administration of VCO polyphenols and Cd on serum renal function parameters of treated rats

Table 2 depicts the impact of VCO polyphenols and $\mathrm{Cd}$ administration on serum markers of kidney damage in Cd-treated rats. Nephrotoxic effect of $\mathrm{Cd}$ was evident by significant increases $(p<0.05)$ in serum levels of creatinine, urea and uric acid compared to control (Table 2). The VCO polyphenols (10, 20 and $50 \mathrm{mg} / \mathrm{kg}$ ) administered prior to and concurrently with $\mathrm{Cd}$ attenuated and reversed the nephrotoxicity induced by $\mathrm{Cd}$. This was demonstrated by remarkable reduction $(p<0.01)$ in the levels of creatinine, urea and uric acid in group $\mathrm{PF}+\mathrm{Cd} \mathrm{I}, \mathrm{PF}+\mathrm{Cd} \mathrm{II}$, and $\mathrm{PF}+\mathrm{Cd}$ III compared to Cd group.

\section{Antioxidant activity of polyphenol fraction}

Table 3 shows the estimation of total phenol content, DPPH scavenging activity and ferric reducing antioxidant power of methanol-extracted polyphenol fraction.

Effects of administration of VCO polyphenols and Cd on renal markers of oxidative stress in treated rats

The sub-chronic administration of $\mathrm{Cd}(5 \mathrm{mg} / \mathrm{kg})$ significantly decreased $(p<0.01)$ renal activities of SOD, CAT, and GPx, as well as renal level of non-enzymatic antioxidant, GSH, compared to control as shown in Figs. 1-4. Marker of lipid peroxidation, MDA significantly increased $(p<0.01)$ in renal tissue of rats treated with Cd (Fig. 5). The levels of SOD, CAT, GPx GSH, and MDA were comparable to control in rats administered VCO polyphenols

Table 2

Effects of administration of VCO polyphenols and Cd on serum creatinine, urea and uric acid in treated rats.

\begin{tabular}{llll}
\hline Group & Creatinine $(\mathrm{mg} / \mathrm{dl})$ & Urea $(\mathrm{mg} / \mathrm{dl})$ & Uric acid $(\mathrm{mg} / \mathrm{dl})$ \\
\hline Control & $1.61 \pm 0.03$ & $43.3 \pm 0.54$ & $4.32 \pm 0.08$ \\
PF & $1.49 \pm 0.06$ & $38.3 \pm 1.21^{*}$ & $4.43 \pm 0.07$ \\
Cd & $2.09 \pm 0.10^{*}$ & $59.0 \pm 1.34^{*}$ & $5.67 \pm 0.11^{*}$ \\
PF + Cd I & $1.66 \pm 0.12^{\#}$ & $40.9 \pm 0.90^{\#}$ & $5.19 \pm 0.03^{\#}$ \\
PF + Cd II & $1.24 \pm 0.06^{\#}$ & $35.8 \pm 1.01^{\#}$ & $5.19 \pm 0.04^{\#}$ \\
PF + Cd III & $0.99 \pm 0.04^{\#}$ & $29.2 \pm 1.80^{\#}$ & $5.09 \pm 0.04^{\#}$ \\
\hline
\end{tabular}

PF: polyphenols; Cd: cadmium; PF + Cd I: PF (10 mg/kg) + Cd (5 mg/kg); PF + Cd II: PF $(20 \mathrm{mg} / \mathrm{kg})+\mathrm{Cd}(5 \mathrm{mg} / \mathrm{kg}) ; \mathrm{PF}+\mathrm{Cd}$ III: PF $(50 \mathrm{mg} / \mathrm{kg})+\mathrm{Cd}(5 \mathrm{mg} / \mathrm{kg})$. Values are expressed as mean \pm SEM $(n=8) .{ }^{*} p<0.05$ : the difference is significant when compared to control group, ${ }^{\#} p<0.01$ : the difference is significant when compared to Cd group. 
Table 3

The total phenol content, DPPH scavenging activity and ferric reducing antioxidant reducing power (FRAP) of polyphenol fraction using 80\% methanol.

\begin{tabular}{ll}
\hline Total phenol content $(\mathrm{mg} \mathrm{GAE} / 100 \mathrm{~g})$ & DPPH scavenging activity (\%) \\
\hline $57.11 \pm 0.05$ & $68.24 \pm 0.10$ \\
\hline
\end{tabular}

Values represent mean \pm SEM of triplicate analysis. DPPH: 1, 1-diphenyl-2-picrylhydrazyl; GAE: gallic acid equivalent per $100 \mathrm{~g}$ oil.

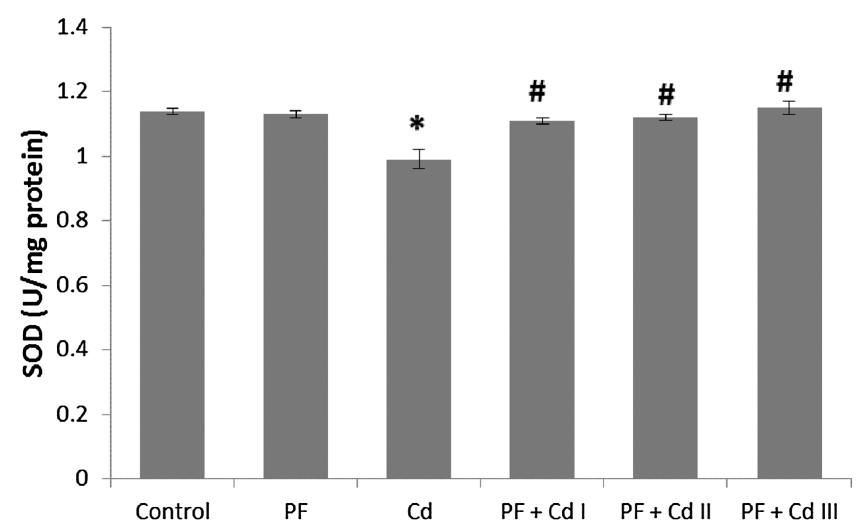

Fig. 1. Effect of VCO polyphenols and $\mathrm{CdCl}_{2}$ on renal superoxide dismutase (SOD) activity in treated rats. Results were expressed as mean $\pm \operatorname{SEM}(n=8) ;{ }^{*} p<0.01$ : the difference is significant compared to control group; $\# p<0.01$ : the difference is significant compared to $\mathrm{CdCl}_{2}$ group.

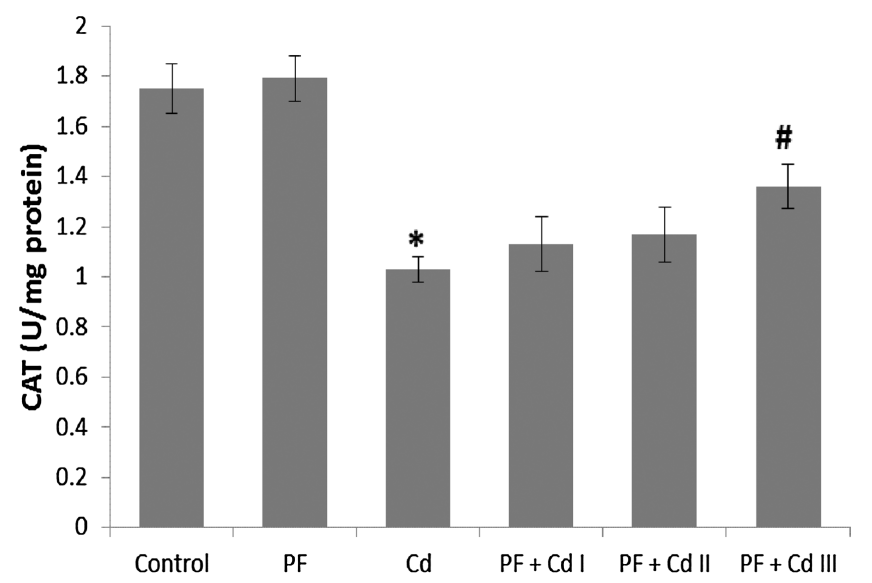

Fig. 2. Effect of polyphenols and $\mathrm{CdCl}_{2}$ administration on renal catalase (CAT) activity in treated rats. Results were expressed as mean $\pm \operatorname{SEM}(n=8), p<0.05$ was considered significant. ${ }^{*} p<0.01$ : the difference is significant compared to control group; $\# p<0.01$ : the difference is significant compared to $\mathrm{CdCl}_{2}$ group.

(20 mg/kg) only. Interestingly, the administration of VCO polyphenols $(10,20$ and $50 \mathrm{mg} / \mathrm{kg}$ ) prior to and along with Cd exposure in group PF + Cd I, II and III (except CAT in I and II) significantly prevented alterations in SOD, CAT, GPx, and GSH and lipid peroxidation marker, MDA, compared to Cd group $(p<0.01)$ and comparable $(p>0.01)$ to normal control rats.

Effect of administration of VCO polyphenols and $\mathrm{CdCl}_{2}$ on serum levels of inflammatory markers in treated rats

In Figs. 6-7, the effect of VCO polyphenols and $\mathrm{CdCl}_{2}$ on serum levels of C-reactive protein (CRP), interleulin-6 (IL-6) and nitric oxide (NO) were shown. It was observed that Cd significantly triggered inflammatory responses evident by prominent increases $(p<0.01)$ in serum levels of C-reactive protein (CRP), interleulin-6 (IL-6) and nitric oxide (NO) compared to control. However, VCO polyphenol administration prior to and concurrently with $\mathrm{CdCl}_{2}$

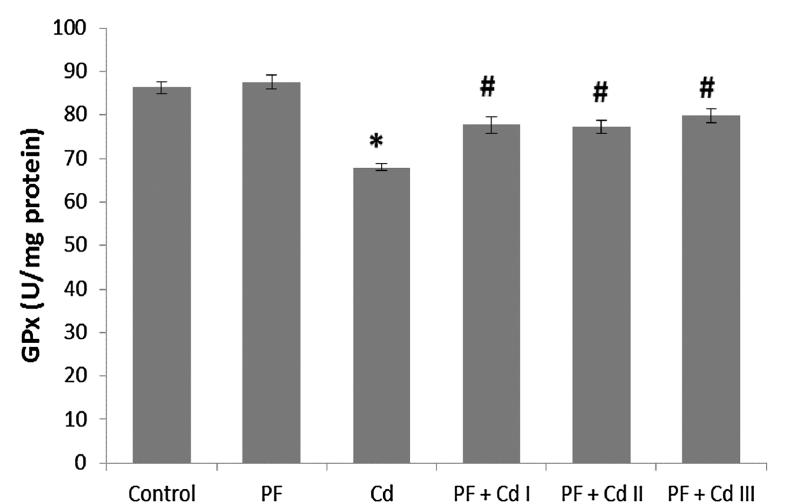

Fig. 3. Effect of polyphenols and $\mathrm{CdCl}_{2}$ administration on renal glutathione peroxidase (GPx) activity in treated rats. Results were expressed as mean \pm SEM $(n=8), p<0.05$ was considered significant. ${ }^{*} p<0.01$ : the difference is significant compared to control group; ${ }^{\#} p<0.01$ : the difference is significant compared to $\mathrm{CdCl}_{2}$ group.

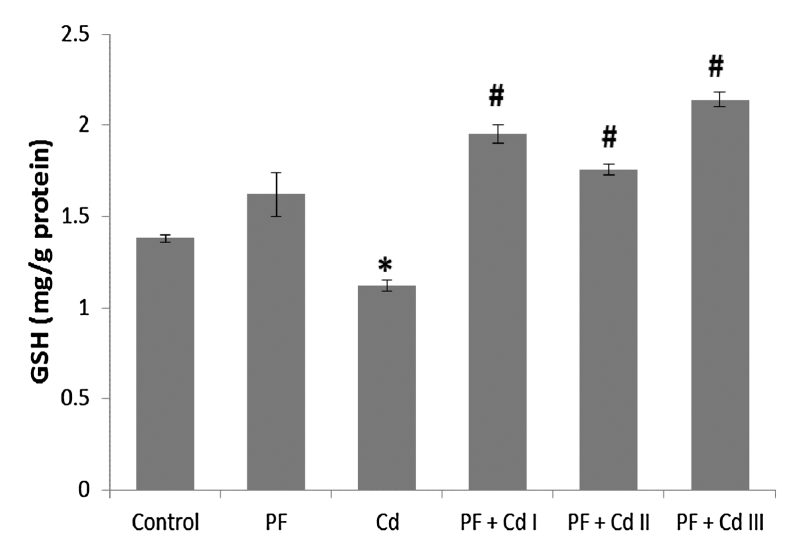

Fig. 4. Effect of polyphenols and $\mathrm{CdCl} 2$ administration on renal reduced glutathione (GSH) level in treated rats. Results were expressed as mean $\pm \operatorname{SEM}(n=8), p<0.05$ was considered significant. ${ }^{*} p<0.01$ : the difference is significant compared to control group; $\# p<0.01$ : the difference is significant compared to $\mathrm{CdCl} 2$ group.

exposure significantly decreased $(p<0.01)$ IL-6 and NO proinflammatory markers dose-dependently when compared to $\mathrm{CdCl}_{2}$ group. Although the impact of VCO polyphenol (20 and $50 \mathrm{mg} / \mathrm{kg}$ ) was considerable on CRP levels, it was observed that there was no significant effect on CRP level in rat group treated with $10 \mathrm{mg} / \mathrm{kg}$ dose of VCO polyphenol.

\section{Kidney histology and histopathology}

As indicated in Fig. 9, light microscopic evaluation revealed normal histomorphology of the kidney tissue in control group evident by normal tubules (black arrow) and glomeruli (G). Similar histological findings were observed in rat group administered VCO polyphenols $(20 \mathrm{mg} / \mathrm{kg}$ ) only. However, Cd-treated group showed histopathological lesions consistent with nephrotoxic renal tubular degeneration, lymphocytic infiltration and necrosis in the cortex and outer medullar (black arrow). VCO polyphenol 


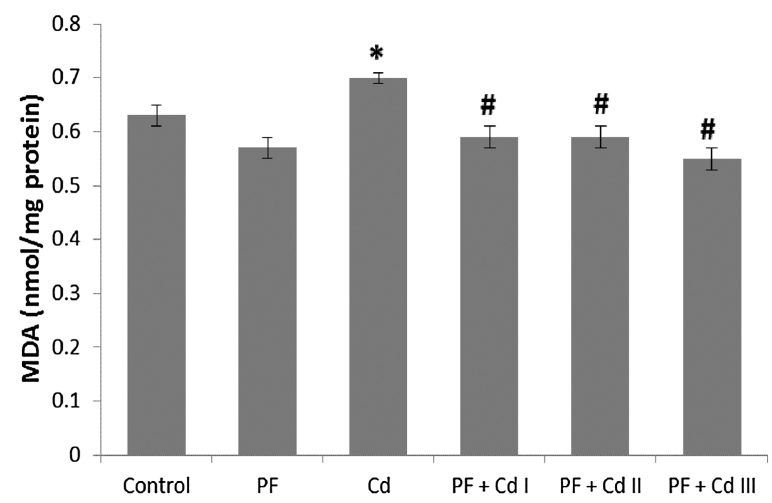

Fig. 5. Effects of polyphenols and $\mathrm{CdCl}_{2}$ administration on renal malondialdehyde (MDA) level in treated rats. Results were expressed as mean $\pm \operatorname{SEM}(n=8), p<0.05$ was considered significant. ${ }^{*} p<0.01$ : the difference is significant compared to control group; ${ }^{\#} p<0.01$ : the difference is significant compared to $\mathrm{CdCl}_{2}$ group.

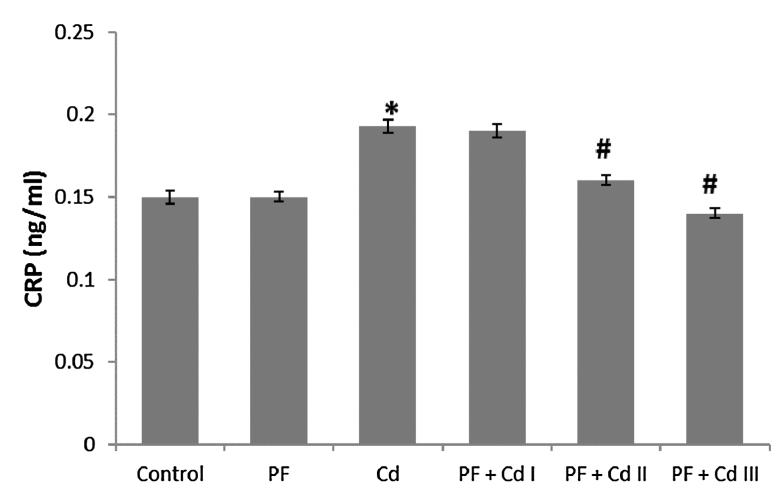

Fig. 6. Effect of VCO polyphenols and $\mathrm{CdCl}_{2}$ administration on serum C-reactive protein (CRP) level in treated rats. Results were expressed as mean $\pm \operatorname{SEM}(n=8)$, $p<0.05$ was considered significant. ${ }^{*} p<0.01$ : the difference is significant compared to control group; ${ }^{\#} p<0.01$ : the difference is significant compared to Cd group.

administration demonstrated dose-dependent improvement on kidney damage with near normal tubular cells (black arrow) and glomerulus (G).

\section{Discussion}

Cadmium is a well-known environmental toxicant associated with pathological changes in target organs, including the kidney.

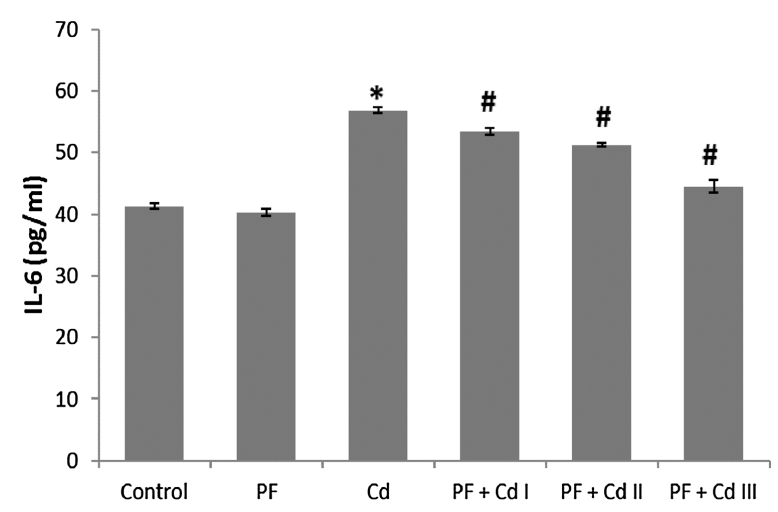

Fig. 7. Effects of $\mathrm{VCO}$ polyphenols and $\mathrm{CdCl}_{2}$ administration on serum interleukin- 6 (IL-6) level in treated rats. Results were expressed as mean $\pm \operatorname{SEM}(n=8), p<0.05$ was considered significant. ${ }^{*} p<0.01$ : the difference is significant compared to control group. ${ }^{*} p<0.01$ : the difference is significant compared to Cd group.

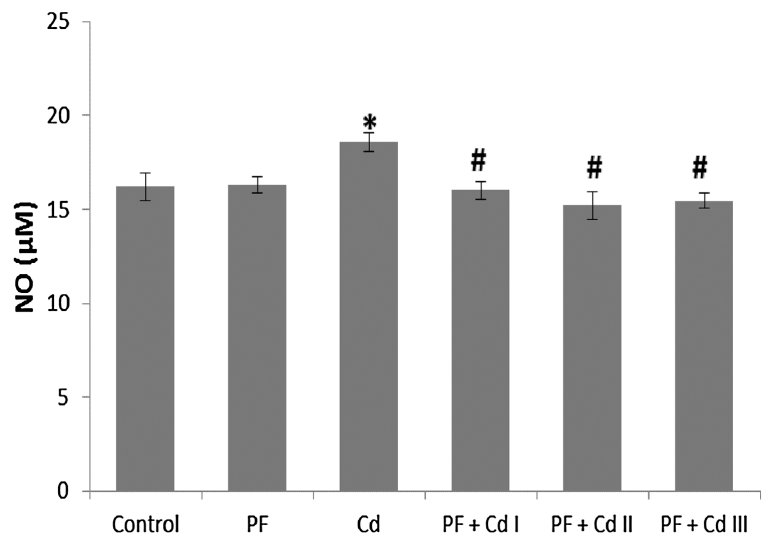

Fig. 8. Effects of VCO polyphenols and $\mathrm{CdCl}_{2}$ administration on serum nitric oxide (NO) level in treated rats. Results were expressed as mean $\pm \operatorname{SEM}(n=8){ }^{*} p<0.05$ : the difference is significant compared to control group; ${ }^{\#} p<0.01$ : the difference is significant compared to Cd group.

Cadmium toxicity is attributed to depletion of cellular sulfhydryl reserves and consequent oxidative stress implicated in oxidative renal damage in humans and animals (Renugadevi and Prabu, 2009). The current chelation approaches are unsatisfactory and ineffective in chronic exposure and are incapable of promoting metal excretion from cells (Flora and Pachauri, 2010). Also, use of synthetic antioxidants has decreased due to suspected activity as carcinogenic promoters (Rojas et al., 2012; Umeno et al., 2016). The current study, for the first time, provides experimental evidence of the beneficial effect of VCO polyphenols on Cd-induced nephrotoxicity and pro-inflammatory responses.

In the present study, the sub-chronic oral Cd administration was found to cause marked renal dysfunction evident by increased serum creatinine and urea levels diagnostic indicators of glomerular filtration rate reduction and nephrotoxicity (Shahani et al., 2016), accompanied by prominent increase in uric acid level. Earlier studies indicate that Cd toxicity damages mesangial cells of the glomerulus, disrupts the glomerular capillary network leading to impairment in glomerular ultrafiltration (Chen et al., 2016). Hughes et al. (1996) found ROS involvement in the impairment of glomerular filtration rate. Thus, the mechanism of Cd-induced impairment in glomerular filtration may be associated with $\mathrm{Cd}$ induced oxidative stress. It is conceivable that compromised glomerular filtration capacity could result in significantly increased levels of creatinine, urea and uric acid observed in this study (Deevika et al., 2012). The co-administration of VCO polyphenols with $\mathrm{Cd}$ protects the kidney from $\mathrm{Cd}$ intoxication as indicated by significant restoration of serum creatinine, urea, and uric acid levels comparable to control. The restorative effect of VCO polyphenols on the kidney markers can be attributed to its antioxidant and radical trapping properties associated with its constituent bioactive phenolic acids and flavonoids (Illam et al., 2017) Our observation corroborates the previous findings of systematic investigations in which polyphenol fraction was reported to protect gentamicin-induced nephrotoxicity through its antioxidant capacity (Shahani et al., 2016; Yamana and Balikci, 2010).

Redox impairment is associated with enhanced ROS generation. The ability of Cd to induce ROS and oxidize sulphydryl groups via indirect mechanism is consistent with oxidative stress (Liu et al., 2009; Rizwan et al., 2014). In this study, Cd treatment deteriorates renal antioxidant defence system demonstrated by significant depression in activities of SOD, CAT, GPX and GSH in the kidney. The inhibition of SOD, CAT, GPx activity and GSH level exacerbate accumulation of ROS which promotes lipid peroxidation and oxidative damage in kidney tissue, hence marked increase in MDA 

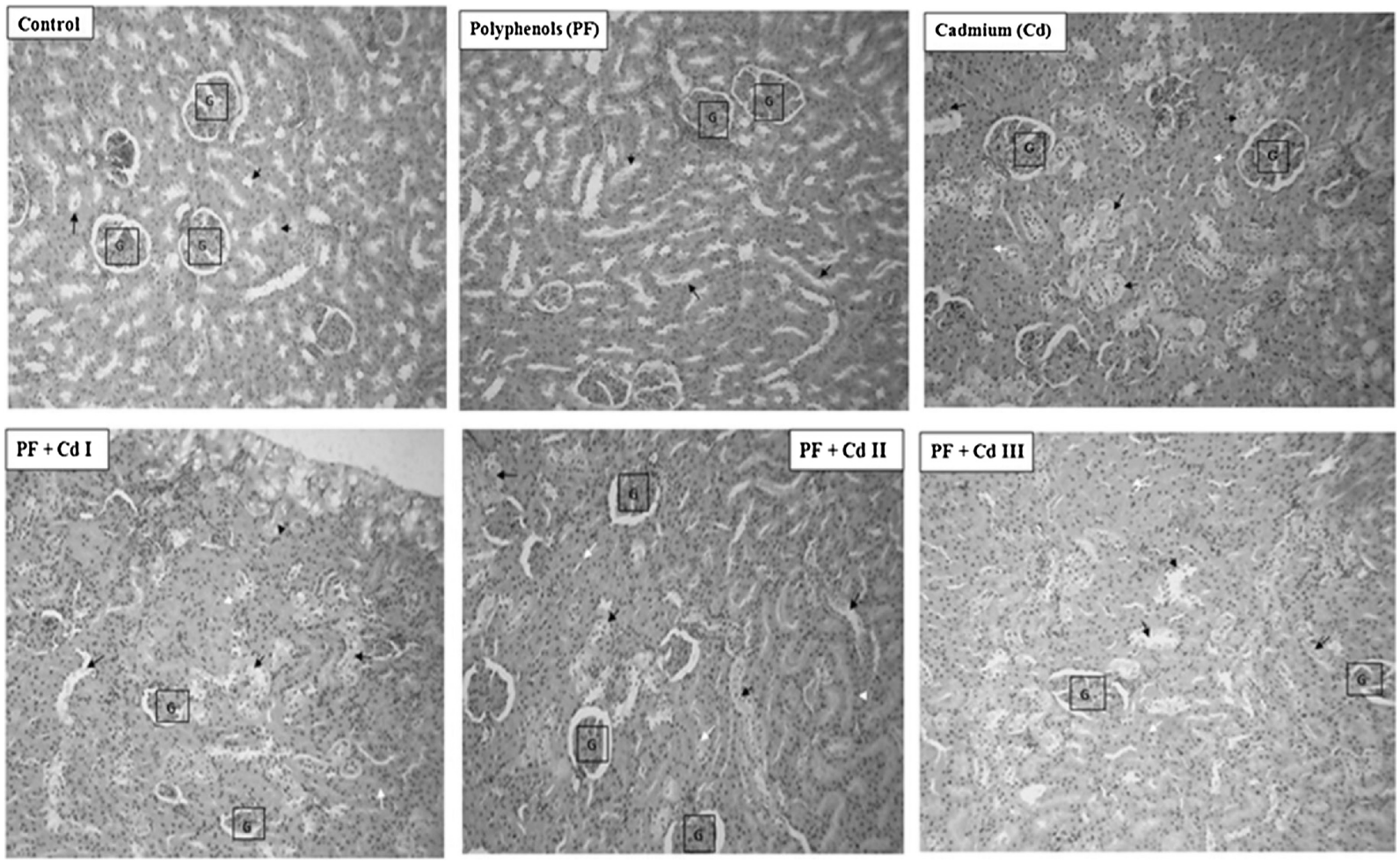

Fig. 9. Photomicrographs of kidney sections showing the effect of VCO polyphenols and Cd administration on renal architecture. Control and VCO polyphenol groups showed normal histomorphology with normal tubules (black arrow) and glomeruli $(\mathrm{G})$. Cadmium ( $5 \mathrm{mg} / \mathrm{kg}$ ) group showed histopathological lesions, including multifocal tubular degeneration, lymphocyte infiltration and necrosis (black arrow). Concurrent treatment of VCO polyphenols with cadmium in groups, PF + Cd I, PF + Cd II and PF + Cd III showed improvement dose-dependently particularly in $50 \mathrm{mg} / \mathrm{kg}$ doses of VCO polyphenols administration.

level in the present study (Farooqui et al., 2017). However, the mechanism by which Cd inhibits antioxidant enzymes may be explained by $\mathrm{Cd}$ interaction at enzyme active site and/or their consumption to overcome the preponderance influx of ROS in $\mathrm{Cd}$ nephrotoxicity. Recent papers indicate that direct binding of $\mathrm{Cd}$ to thiol (-SH) group of cysteine or imidazole group of histidine in SOD or GPx may result in their depressed activities in kidney (Deevika et al., 2012; Farooqui et al., 2017; Valentovic et al., 2014). The displacement of cofactor Fe from CAT, $\mathrm{Zn}$ from SOD and selenium from GPx by Cd is also reported to deactivate these enzymes implying possible failure of antioxidant defence mechanism to trap ROS (Choi et al., 2016; Patra et al., 2011; Xiao, 2016). Moreover, GSH and other -SH-containing proteins play critical role in redox homeostasis. Evidences indicate that depletion of GSH via indirect mechanism of Cd-induced oxidative stress precedes lipid peroxidation and nephrotoxicity (Morales et al., 2006; Patra et al., 2011). In agreement with this finding, we have observed in the present study that renal content of MDA considerably increased in $\mathrm{Cd}$ control rats. MDA is the most important abundant aldehyde product of lipid peroxidation (LPO) in biological systems (Halliwell and Gutteridge, 1999; Hamza, 2010). MDA is of significant concern because of its mutagenic and carcinogenic effects implicated in pathological processes (El-Sharaky et al., 2009). In this study, elevated MDA coincides with nephrotoxicity induced by $\mathrm{Cd}$. However, administration of VCO polyphenols prior to and along with $\mathrm{Cd}$ treatment attenuated the $\mathrm{Cd}$-induced decrease in renal SOD, CAT and GPx activity as well as non-enzymatic GSH level. In addition, the improved antioxidant defence mechanism provoked inhibition of LPO in renal tissue shown by marked reduction in MDA. The protective effect of VCO against Cd nephrotoxicity could be associated with its radical scavenging ability by neutralizing the radical species before they reach their renal targets. The consequent reduction in LPO and improved antioxidant defence could have contributed to recovery in renal histology and dosedependent efficacy of VCO polyphenols in the attenuation of Cd nephrotoxicity. The antioxidant activity of the VCO polyphenols was confirmed by DPPH radical scavenging activity attributed to its hydrogen donating ability (Table 3). Estimation from FRAP assay shows considerable reducing power exhibited by VCO polyphenols. The presence of polyphenols in VCO polyphenol fraction was established in this study by total phenolic content (Table 3 ). The earlier work of Marina et al. (2009) has shown that ferulic and $p$-coumaric acids are the major phenolic acids in VCO. Ferulic and p-coumaric acids are phenolic acids reported to possess antioxidant and anti-inflammation properties (Marina et al., 2009; Shi et al., 2016). The free radical scavenging properties of ferulic and p-coumaric acids and other flavonoids could contribute to antioxidant and nephroprotective effects of VCO polyphenols fraction in this study (Srivastava et al., 2016).

Evidences indicate that oxidative stress promotes pro-inflammatory responses implicated in Cd nephrotoxicity (Afolabi et al., 2013; Shahani et al., 2016). It is known that NO may combine with oxygen radicals to form potent oxidants like peroxynitrite that participates in oxidative damage to cells and tissue. Thus, the inflammatory action of $\mathrm{Cd}$ could be initiated or enhanced by the generation of ROS. In the present study, we found that the nephrotoxic effect of Cd was accompanied by increased levels of inflammatory markers, CRP, IL-6 and NO in Cd-treated rats. Notably, the present study, in agreement with previous studies (Afolabi et al., 2013; Shahani et al., 2016), shows that oxidative stress resulting from depletion of antioxidant defence triggers release of pro-inflammatory mediators in the pathogenesis of $\mathrm{Cd}$ nephrotoxicity. However, co-administration of VCO polyphenols with Cd remarkably inhibited increase in CRP, IL-6 and NO (Figs. 68). Production of pro-inflammatory cytokines, such as tumour necrosis factor- $\alpha$ and IL- 6 is associated with $\mathrm{Cd}$ intoxication 
(Afolabi et al., 2013). IL-6 triggers acute phase reaction contributing to increase in CRP in Cd-treated rats in the current study (Colacino et al., 2014). Interestingly, the administration of VCO polyphenols prevented increase in levels of IL-6 and CRP. This observation suggests anti-inflammatory potential of VCO polyphenols. Nitric oxide (NO) is a diffusible short-lived free radical gas with physiological and pathological functions in mammalian tissues (Vysakh et al., 2014). It has been demonstrated that Cd upregulates inducible nitric oxide synthase (iNOS) resulting in increased NO production implicated in Cd-mediated cytotoxicity and oxidative damage (Fouad et al., 2009). Reduction of NO level in the current study may be associated with reduction in the activity of iNOS and oxidative stress as earlier reported (Manikandan et al., 2011). The obtained result is consistent with the report of Vysakh et al. (2014) that polyphenolic fraction of VCO modulates oxidative stress and inflammation in experimental model of arthritis. Regarding the role of these mediators in the pathobiochemical mechanism that promotes kidney nephrotoxicity and inflammation, VCO polyphenols could inhibit Cd-induced nephrotoxicity via mitigation of oxidative stress and inflammation confirmed by marked suppression of necrotic degeneration and infiltration of inflammatory cells in rat kidney co-administered VCO polyphenols and $\mathrm{Cd}$.

\section{Conclusions}

The current study has confirmed that VCO polyphenols affords nephroprotective effect against nephrotoxicity induced by $\mathrm{Cd}$ mediated oxidative stress and inflammatory responses. Based on our biochemical findings, which were supported by histopathological analysis, VCO polyphenol fraction protected the kidney from Cd toxicity via improvement in antioxidant defence systems and its anti-inflammatory activity. Accordingly, VCO polyphenols could be used as food supplement for the prevention of toxicity of environmental toxicants such as $\mathrm{Cd}$ in humans.

\section{Conflict of interests}

The authors declared no potential conflict of interests with respect to the research, authorship, and/or publication of this article.

This paper was a part of the Ph.D. thesis of Ademola C. Famurewa at the Department of Medical Biochemistry, Faculty of Basic Medical Sciences, College of Medicine, University of Nigeria, Enugu Campus.

\section{Acknowledgements}

One of the authors (Ademola C. Famurewa) is a beneficiary of ARL 2017 Biomedical/Clinical Research Grant. Therefore, the authors would like to acknowledge that this work was financially supported by the research grant received from ARL 2017 Biomedical/Clinical Research Grant, African Research League in collaboration with the College of Medicine, University of Nigeria, Nigeria. In addition, this work was a part of the Ph.D. thesis of the first author submitted to the Department of Medical Biochemistry, College of Medicine, University of Nigeria, UNEC campus.

\section{References}

Afolabi, O.K., Oyewo, E.B., Adekunle, A.S., Adedosu, O.T., Adedeji, A.L., 2013. Oxidative indices correlate with dyslipidemia and pro-inflammatory cytokine levels in fluoride-exposed rats. Arh Hig Rada Toksikol. 64, 521-529.

Akinnuga, A.M., Jeje, S.O., Bamidele, O., Amaku, E.E., Otogo, F.O., Sunday, V.E., 2014. Virgin coconut oil: remedial effects on renal dysfunction in diabetic rats. Physiol. J. 2014, 1-5. doi:http://dx.doi.org/10.1155/2014/495926.
Andersen, H.C., McCarthy, M., 1950. Determination of C-reactive protein in the blood as a measure of the activity of the disease process in acute rheumatic fever. Am. J. Med. 8, 445-455.

Arthur, J.R., Boyne, R., 1985. Superoxide dismutase and glutathione peroxidase activities in neutrophils from selenium deficient and copper deficient cattle. Life Sci. 36 (16), 1569-1575.

Arunima, S., Rajamohan, T., 2013. Effect of virgin coconut oil enriched diet on the antioxidant status and paraoxonase 1 activity in ameliorating the oxidative stress in rats - a comparative study. Food Funct. 4, 1402-1409.

Barregard, L., Sallsten, G., Fagerberg, B., Borné, Y., Persson, M., Hedblad, B., Engström, G., 2016. Blood cadmium levels and incident cardiovascular events during follow-up in a population based cohort of Swedish adults: The Malmö Diet and Cancer Study. Environ. Health Perspect. 124, 594-600.

Bernard, A., 2016. Confusion about cadmium risks: the unrecognized limitations of an extrapolated paradigm. Environ. Health Perspect. 124, 1-5.

Blois, M.S., 1958. Antioxidant determinations by the use of a stable free radical. Nature 26, 1199-1200.

Chen, X., Li, J., Cheng, Z., Xu, Y., Wang, X., Li, X., 2016. Low dose cadmium inhibits proliferation of human renal mesangial cells via activation of the JNK pathway. Int. J. Environ. Res. Public Health 13, 990-1001.

Choi, K.H., Lee, H.A., Park, M.H., Han, J., 2016. Mulberry (Morus alba L.) fruit extract containing anthocyanins improves glycaemic control and insulin sensitivity via activation of amp-activated protein kinase in diabetic $\mathrm{C} 57 \mathrm{BL} / \mathrm{Ksj}-\mathrm{db} / \mathrm{db}$ mice. J. Med. Food 19 (8), 737-745.

Colacino, J.A., Arthur, A.E., Ferguson, K.K., Rozek, L.S., 2014. Dietary antioxidant and anti-inflammatory intake modifies the effect of cadmium exposure on markers of systemic inflammation and oxidative stress. Environ. Res. 131, 6-12.

Deevika, B., Asha, S., Taju, G., Nalini, T., 2012. Cadmium acetate induced nephrotoxicity and protective role of curcumin in rats. Asian J. Pharm. Clin. Res. 5 (Suppl. 3), 186-188.

El-Sharaky, A.S., Newairy, A.A., Kamel, M.A., Eweda, S.M., 2009. Protective effect of ginger extract against bromobenzene-induced hepatotoxicity in male rats. Food Chem. Toxicol. 47, 1584-1590.

Exner, R., Wessner, B., Manhart, N., Roth, E., 2000. Therapeutic potential of glutathione. Wien Klin. Wochenschr. 112, 610-616.

Fagerberg, B., Kjelldahl, J., Sallsten, G., Barregard, L., Forsgard, N., Österberg, K., et al., 2016. Cadmium exposure as measured in blood in relation to macrophage density in symptomatic atherosclerotic plaques from human carotid artery. Atherosclerosis 249, 209-214.

Famurewa, A.C., Ufebe, O.G., Egedigwe, C.A., Nwankwo, O.E., Obaje, G.S., 2017. Virgin coconut oil supplementation attenuates acute chemotherapy hepatotoxicity induced by anticancer drug methotrexate via inhibition of oxidative stress in rats. Biomed. Pharmacother. 87, 437-442.

Farooqui, Z., Ahmed, F., Rizwana, S., Shahida, F., Khan, A.A., Khan, F., 2017. Protective effect of Nigella sativa oil on cisplatin induced nephrotoxicity and oxidative damage in rat kidney. Biomed. Pharmacother. 85, 7-15.

Flora, S.J., Pachauri, V., 2010. Chelation in metal intoxication. Int. J. Environ. Res. Public Health 7, 2745-2788.

Fouad, A.A., Qureshi, H.A., Al-Sultan, A.I., Yacoubi, M.T., Ali, A.A., 2009. Protective effect of hemin against cadmium-induced testicular damage in rats. Toxicology 257, 153-160.

Green, L.C., Wagner, D.A., Glogowski, J., Skipper, P.L., Wishnok, J.S., Tannenbaum, S.R. 1982. Analysis of nitrate, nitrite, and $\left[{ }^{15} \mathrm{~N}\right]$ nitrate in biological fluids. Anal. Biochem. 126, 131-138.

Guide for the Care and the Use of Laboratory Animals, 2011. Washington: National Academic Press, pp. 85-123. [online] [cit. 2017-05-12]. Available from: https:// grants.nih.gov/grants/olaw/guide-for-the-care-and-use-of-laboratory-animals pdf.

Hagar, H., Almalki, W., 2014. Betaine supplementation protects against renal injury induced by cadmium intoxication in rats: role of oxidative stress and caspase- 3 . Environ. Toxicol. Pharmacol. 37, 803-811.

Halliwell, B., Gutteridge, J.M., 1999. Free Radicals in Biology and Medicine. Oxford University Press, Oxford.

Hamza, A.A., 2010. Ameliorative effects of Moringa oleifera Lam seed extract on live fibrosis in rats. Food Chem. Toxicol. 48, 345-355.

Hughes, A.K., Stricklett, K., Padilla, E., Kihan, D.E., 1996. Effect of reactive oxygen species on endothelin-1 production by human mesangial cells. Kidney Int. 49 181-189.

Illam, S.P., Narayanankutty, A., Raghavamenon, A.C., 2017. Polyphenols of virgin coconut oil prevent pro-oxidant mediated cell death. Toxicol. Mech. Methods 27 (6), 442-450.

Järup, L., Akesson, A., 2009. Current status of cadmium as an environmental health problem. Toxicol. Appl. Pharmacol. 238 (3), 201-208.

Khanna, P., Ong, C., Bay, B.H., Baeg, G.H., 2015. Nanotoxicity: an interplay of oxidative stress, inflammation and cell death. Nanomaterials 5, 1163-1180.

Liu, J., Qu, W., Kadiiska, M.B., 2009. Role of oxidative stress in cadmium toxicity and carcinogenesis. Toxicol. Appl. Pharmacol. 238, 209-214.

Manikandan, R., Beulaja, M., Thiagarajan, R., Priyadarsini, A., Saravanan, R. Arumugam, M., 2011. Ameliorative effects of curcumin against renal injuries mediated by inducible nitric oxide synthase and nuclear factor kappa B during gentamicin-induced toxicity in Wistar rats. Eur. J. Pharmacol. 670, 578-585.

Marina, A.M., Che-Man, Y.B., Nazimah, S.A., Amin, I., 2009. Antioxidant capacity and phenolic acids of virgin coconut oil. Int. J. Food Sci. Nutr. 60 (S2), 114-123.

Morales, A.I., Vicente-Sánchez, V., Sandoval, J.M., Egido, J., Mayoral, P., Arévalo, M.A. et al., 2006. Protective effect of quercetin on experimental chronic cadmium 
nephrotoxicity in rats is based on its antioxidant properties. Food Chem. Toxicol. 44, 2092-2100.

Nevin, K.G., Rajamohan, T., 2004. Beneficial effects of virgin coconut oil on lipid parameters and in vitro LDL oxidation. Clin. Biochem. 37, 830-835.

Nordberg, G.F., Nogawa, K., Nordberg, M., 2015. Cadmium. In: Nordberg, G.F., Fowler, G.F., Nordberg, M. (Eds.), Handbook on the Toxicology of Metals. Elsevier, Amsterdam, pp. 667-716.

Ojo, O.A., Ajiboye, B.O., Oyinloye, B.E., Ojo, A.B., Olarewaju, O.I., 2014. Protective effect of Irvingia gabonensis stem-bark extract on cadmium-induced nephrotoxicity in rats. Interdiscip. Toxicol. 7 (4), 208-214.

Oyaizu, M., 1986. Studies on products of browning reaction: antioxidative activities of products of browning reaction prepared from glucosamine. Jpn. J. Nutr. 44, 307-315.

Paglia, D.E., Valentine, W.N., 1967. Studies on the quantitative and qualitative characterization of erythrocyte glutathione peroxidase. J. Lab. Clin. Med. 70, 158-169.

Patra, R.C., Rautray, A.K., Swarup, D., 2011. Oxidative stress in lead and cadmium toxicity and its amelioration. Vet. Med. Int. 2011, 1-9. doi:http://dx.doi.org/ $10.4061 / 2011 / 457327$

Prozialeck, W.C., Edwards, J.R., 2012. Mechanisms of cadmium-induced proximal tubule injury: new insights with implications for biomonitoring and therapeutic interventions. J. Pharm. Exp. Ther. 343 (1), 2-12.

Rahim, N.S., Lim, S.M., Mani, V., Abdul-Majeed, A., Ramasamy, K., 2017. Enhanced memory in Wistar rats by virgin coconut oil is associated with increased antioxidative, cholinergic activities and reduced oxidative stress. Pharm. Biol. 55 (1), 825-832.

Renugadevi, J., Prabu, S.M., 2009. Naringenin protects against cadmium-induced oxidative renal dysfunction in rats. Toxicology 256, 128-134.

Rizwan, S., Naqshbandi, A., Farooqui, Z., Khan, A.A., Khan, F., 2014. Protective effect of dietary flaxseed oil on arsenic-induced nephrotoxicity and oxidative damage in rat kidney. Food Chem. Toxicol. 68, 99-107.

Rojas, P., Montes, P., Rojas, C., Serrano-García, N., Rojas-Castañeda, J.C., 2012. Effect of a phytopharmaceutical medicine, Ginkgo biloba extract 761, in an animal model of Parkinson's disease: therapeutic perspectives. Nutrition 28, 10811088.

Satarug, S., Garrett, S.H., Sens, M.A., Sens, D.A., 2010. Cadmium, environmental exposure, and health outcomes. Environ. Health Perspect. 118, 182-190.
Seneviratne, K.N., HapuarachchI, C.D., Ekanayake, S., 2009. Comparison of the phenolic-dependent antioxidant properties of coconut oil extracted under cold and hot conditions. Food Chem. 114, 1444-1449.

Shahani, S., Behzadfar, F., Jahani, D., Ghasemi, M., Shaki, F., 2016. Antioxidant and anti-inflammatory effects of Nasturtium officinale involved in attenuation of gentamicin-induced nephrotoxicity. Toxicol. Mech. Methods 27 (2), 107-114.

Shi, C., Zhang, X., Sun, Y., Yang, M., Song, K., Zheng, Z., et al., 2016. Antimicrobial activity of ferulic acid against Cronobacter sakazakii and possible mechanism of action. Foodborne Pathog. Dis. 13 (4), 196-204.

Sinha, A.K., 1972. Colorimetric assay of catalase. Anal. Biochem. 47 (2), 389-394.

Srivastava, Y., Semwal, A.D., Majumdar, A., Yildiz, F., 2016. Quantitative and qualitative analysis of bioactive components present in virgin coconut oil. Cogent Food Agric. 2 (1), 1164929.

Umeno, A., Horie, M., Murotomi, K., Nakajima, Y., Yoshida, Y., 2016. Antioxidative and antidiabetic effects of natural polyphenols and isoflavones. Molecules 21 708-222.

Valentovic, M.A., Ball, J.G., Brown, J.M., Terneus, M.V., McQuade, E., Meter, S.V., et al., 2014. Resveratrol attenuates cisplatin renal cortical cytotoxicity by modifying oxidative stress. Toxicol. in Vitro 28, 248-257.

Vidal, A.C., Semenova, V., Darrah, T., Vengosh, A., Huang, Z., King, K., et al., 2015. Maternal cadmium, iron and zinc levels: DNA methylation and birth weight. BMC Pharmacol. Toxicol. 16, 20-28.

Vysakh, A., Ratheesh, M., Rajmohanan, T.P., Pramod, C., Premlal, S., Girishkumar, B., Sibi, P.I., 2014. Polyphenolics isolated from virgin coconut oil inhibits adjuvant induced arthritis in rats through antioxidant and anti-inflammatory action. Int. Immunopharmacol. 20, 124-130.

Wallin, B., Rosengren, B., Shetzer, H.G., Cameja, G., 1993. Lipid oxidation and measurement of thiobarbituric acid reacting substances (TBARS) formation in a single microtitre plate: its use for evaluation of antioxidants. Anal. Biochem. 208, 10-15.

Wangensteen, H., Samuelsen, A.B., Malterud, K.E., 2004. Antioxidant activity in extracts from coriander. Food Chem. 88 (2), 293-297.

Xiao, J., 2016. Phytochemicals in food and nutrition. Crit. Rev. Food Sci. Nutr. 56 (Suppl. 1), S1-S3.

Yamana, I., Balikci, E., 2010. Protective effects of Nigella sativa against gentamicininduced nephrotoxicity in rats. Exp. Toxicol. Pathol. 62, 183-190.

Zhai, Q., Narbad, A., Chen, W., 2015. Dietary strategies for the treatment of cadmium and lead toxicity. Nutrients 7, 552-571. 